\title{
Are the Roma children "Mentally retarded" if they do not Know the Syntax in their Second Language?
}

\section{H. Kyuchukov (Hristo Kyuchukov)'1, O. Ushakova (Oxana Ushakova)², V. Yashina (Valentina Yashina) $)^{3}$}

${ }^{1}$ University of Silesia, Katowice, Poland

Original Article

2 Russian Academy of Education, Moscow, Russia

${ }^{3}$ Moscow Pedagogical State University, Moscow, Russia

\section{E-mail address:}

hkyuchukov@gmail.com

\section{Reprint address:}

Hristo Kyuchukov

University of Silesia

Katowice

Poland

Source: Clinical Social Work and Health Intervention

Pages: $62-69$

Cited references: 9

\section{Reviewers:}

Peter Polak

MEP of Slovakia

Maria Hardy

St. Elisabeth University of Health and Social Work, Bratislava, Slovakia

\section{Key words:}

Bilingualism. Monolingualism. WH Questions. Syntax. Roma. Russians.

\section{Publisher:}

International Society of Applied Preventive Medicine i-gap

CSWHI 2019; 10(2): 62 - 69; DOI 10.22359/cswhi_10_2_09 (c) 2019 Clinical Social Work and Health Intervention

\section{Abstract:}

This paper presents research among Roma bilingual children from Bulgaria, Croatia, Czech Republic and Slovakia and Russian monolingual children from Russia. The children are tested with the same linguistic test measuring the children's knowledge on the syntax and particularly on the wh-questions. The Roma children $(n=80)$ are tested in their 
second language - the official language of the country of residence, and the Russian children $(n=20)$ are tested in their mother tongue - Russian. All of them are Slavic languages. The syntactic knowledge of both groups of children is compared. The results of the Roma children show that if they have limited knowledge in their mother tongue, their performance of the test in their second language (L2) is also limited. Roma children from Bulgaria and Croatia are much better in performing of the tests in L2, because their mother tongue is stronger in comparison to Roma children from Czech Republic and Slovakia, who demonstrated limited knowledge in their mother tongue. The Russian children show much higher results. They are tested in their mother tongue and the results show that by the age of 6 years more than $80 \%$ of the children can perform the tests correctly.

\section{How monolingual and bilingual children learn a language?}

According to Grosjean (1994:1656) "bilinguals acquire and use their language for different purposes; in different domains of life; with different people. It is precisely because the needs and uses of the languages are usually quite different than the bilinguals really develop equal fluency in their languages. The level of fluency attained in a language (more precisely, in language skill) will depend on the need for that language and will be domain specific. It is thus perfectly normal to find bilinguals who can only read and write one of their languages; who have reduced speaking fluency in a language they only use with a limited number of people; who can only speak about a particular subject in one of their languages."

Studies conducted with pre-school children have proved that mastering the language is not simply an imitation, reproduction of adult speech samples. According to Humboldt (1984) Mastering (native) language, every child relies on vaguely sensed analogies, which are more noticeable in creatively developed children compared to those who rely only on memory. Similar analogies serve as a support to the person, independently, without any help studying foreign language. It is important only to find the spirit of these analogies, and this in any language teaching is a critical point from which the real mastery of the language and the real enjoyment of it begins (p. 347-348). When we say that mastering a language is not just an imitation, not an intuitive (unconscious) process, but first of all the development of linguistic generalizations and the elementary comprehension of linguistic phenomena, that is precisely what we mean by the ,indiscernible consciousness" reasoned presentiment vaguely perceived analogies. Sohin wrote:

„Assimilation of children's mother tongue includes the formation of practical speech skills, improvement of communicative forms and functions of language action (on the basis of practical mastering of means of language), and also formation of comprehension of linguistic validity which can be named linguistic development of the child" (2002, p. 53).

Mastering the syntax of native language by the child is closely connected with cognitive development and development of all sides of speech-phonetic, lexical, morphological. Words, word-combinations, grammatical categories are used in syntactic 
constructions. The study of the syntax of children's speech is necessary to solve the issues of communication development, since it is the syntactic structures that are necessary for speech communications. The language capability syntax includes the generation of self-expression and text.

The following ideas of classical general linguists are relevant to our study:

- According to Humboldt (1836) the language is a systematic body and between language and thinking there is a connection. Today this is a basic concept in modern psycholinguistics.

- de Saussure (1910) developed the idea of systematicity suggested by Humboldt and introduced two terms: "parole" - the speech of individual person and "langue" - the system underlying the speech activity.

- Benveniste (1970) doing a research on the connections between the language and society, says that it is impossible to describe a society, the culture of society without the description of the language.

The idea about the connection between the culture and language exist for decades in psycho-linguistics and sociolinguistics. In our study we try to reflect on this idea.

In Roma culture the children are treated as adults and the expectations from the children is that together with the mother tongue, they have also to learn the official language of the country and very often also another minority language, because Roma usually live next to another minority group in their country of residence. One can say that most Roma children in Europe grow up not just as bilinguals but rather as multilinguals. And to manage two or three or even sometimes more languages from very early age is not an easy task.
There are two approaches to second language acquisition in the psycholinguistic literature:

- The first approach is using the knowledge of the children in their L1 (first language) to investigate what is the influence of L1 into L2 (second language) performance. A number of scientists think that the mother tongue plays an important role in the process of the second language acquisition. Many bilingual children acquire their two languages sequentially (Cummins \& Sayres, 1995; de Hower, 2009; Grosjean, 1982, Cenoz an Genesee, 2001, Kyuchukov, 2016).

It has been proposed that for bilingual children to develop the level of language skill needed to succeed academically in their L2, they must have strong L1 skills. A large body of research shows that there are many ways in which first language skills support second language acquisition.

- A second group of scientists think that the most important is the grammatical structure of the L2. It does not matter what the L1 of the children is, they always will have difficulties learning the L2. Dulay and Burt (1974) were the first to introduce the idea of universal child language learning strategies doing a research with Chinese and Spanish children learning English as L2.

\section{The Study}

The goal of this research is to demonstrate the knowledge of the Roma children on wh- questions in 4 Slavic languages as their L2: Bulgarian, Croatian, Czech and Slovak languages and to compare their knowledge with the knowledge of Russian monolingual children on the same grammatical categories. All languages belong to the family of Slavic languages. The Roma 
children are forming the experimental Group (EG) and the Russian children who's Mother tongue is Russian (L1) are forming the control group (CG).

Research Question: Are the children mentally retarded if they do not know well the wh questions in their L2 by the age of 6 years?

\section{Hypothesis}

H1: Roma children will learn easily the grammatical categories from L2 if they have them well established and developed in their L1.

H2: All Roma children will have the same difficulties learning the same grammatical categories from their L2 because all L2 are Slavic languages.

All the children attend kindergartens and learn the official language organized in the state kindergartens in respective countries: Bulgaria, Croatia, Czech Republic, Slovakia and Russia.

\section{The children}

The Roma children involved in the study are in two age groups: 1 gr. 4-5 years old, and 2 gr. 5-6 years old. The Russian children $(n=20)$ in the study are just one group and they are 5-6 years old. The total number of children involved in the study is 100 . The children were tested individually with a two production tests measuring the knowledge of the children on wh -questions tests, specially developed for this study:

1. Test Wh-questions - 8 items

Who eats what? -2 wh-words

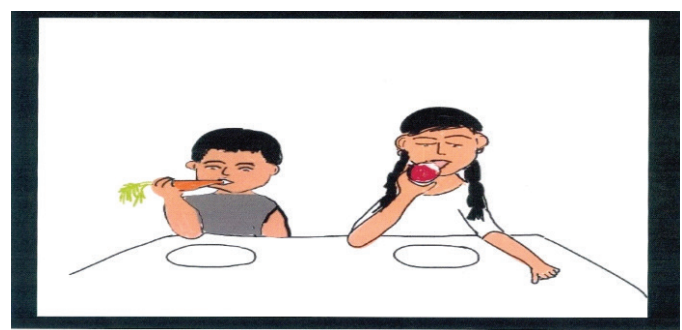

\section{Test Wh compliments}

The woman told the man to catch a mouse, but he caught the cat.

What did the woman tell the man to catch?


\section{Results}

\section{Roma Children}

The Roma children included in this study were tested also in their mother tongue. The results from the Romani testing showed that:

- Bulgarian Roma children have very good knowledge on wh questions in Romani;

- Croatian Roma children (speakers of Romani or/and Albanian) also have good knowledge but not so good as the Bulgarian Roma children;

- Czech Roma children are speakers of Romani and/or ethnolect of Czech language and their knowledge of Romani wh questions were also not so good;

- Slovak Roma children - speakers of an ethnolect of Slovak language and Romani and their knowledge in Romani is also not high. The Russian children are speakers only of Russian as a mother tongue.

Both tests require good knowledge of the second language in order to answer correctly the questions. The results are shown in the following figures. 
Figure 1: Interaction between the factors Age groups and Languages in performance of whquestions test

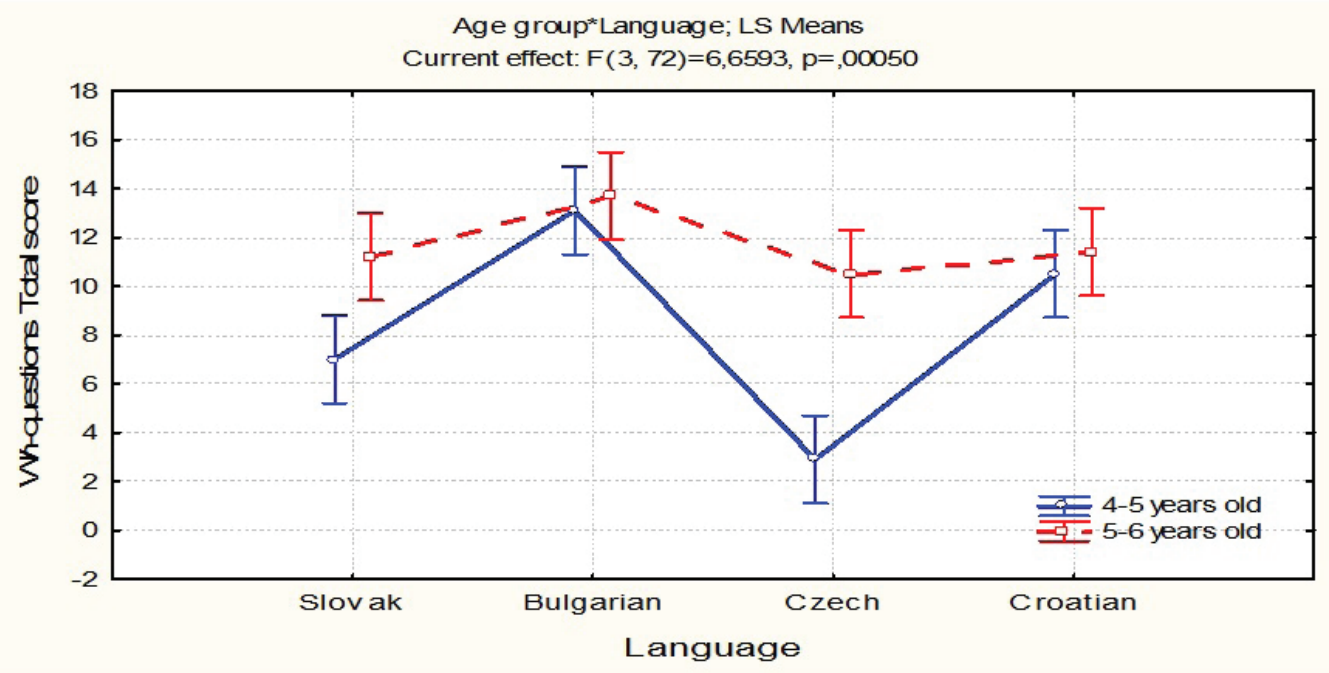

The results from the first testing with wh-questions show statistically significant differences between the age groups from different countries. It is shown that the children from Bulgaria (5-6 years old) are the best in the performance of this test, followed by the Croatian Roma children. The children form Slovakia and Czech Republic show lower results.
In the performance of the second test (wh compliments) the 5-6 years old children again show better results in comparison with the 4-5 years old children. The results are shown in the next Figure 2. The difference between the age groups is statistically significant $(\mathrm{p}<0.00052)$.

Figure 2: Performing of Wh-compliment test by age groups

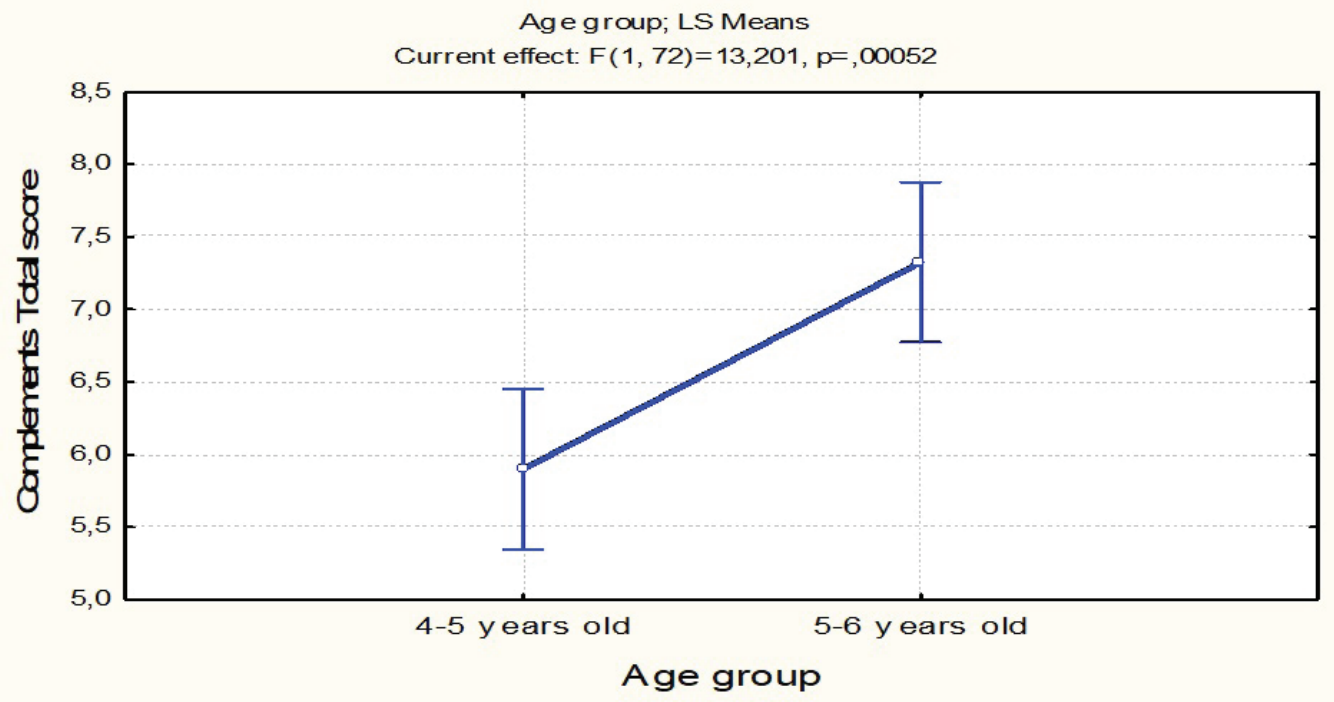


When we compare the results of the children performing this test by country, we get the following picture, shown in the next Figure 3. consistency and systematicity of the language we can conclude that the L2 can be learned in a systematic way if the L1 is learned systematically. The way how the

Figure 3: Performance of Wh- complement test by country

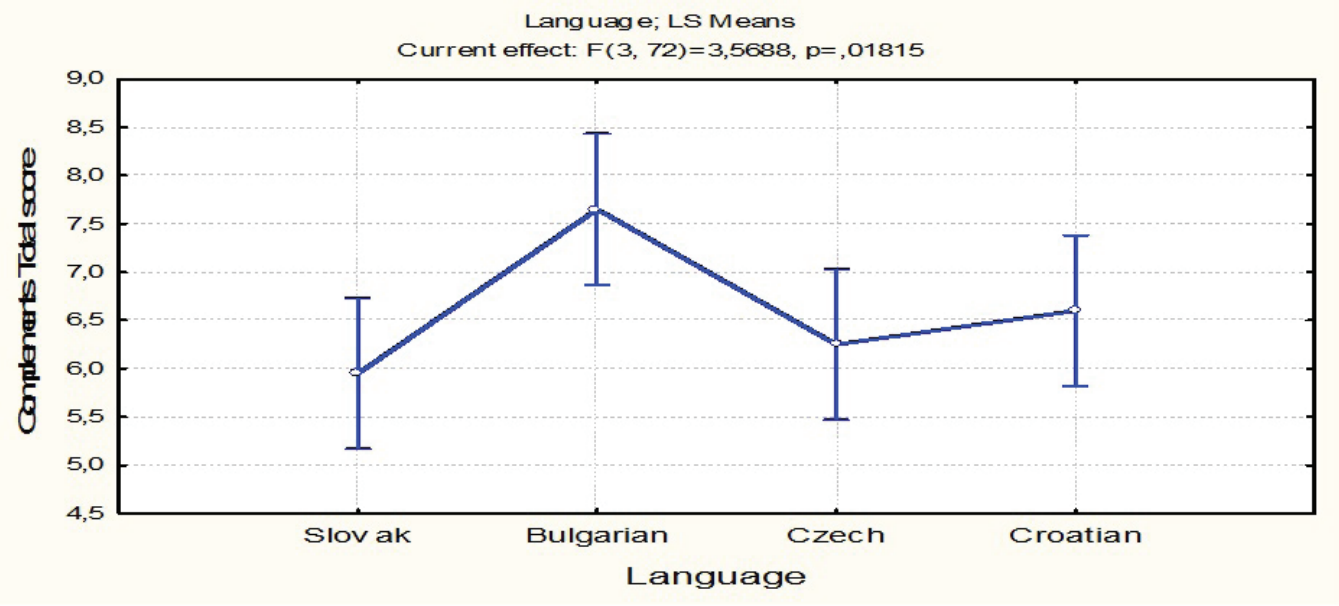

From Figure 3, it is clear that Bulgarian children show much higher results, followed by Croatian and Czech Roma children and the lowest results are shown by the Slovak children. The differences between countries are statistically significant. One of the reasons for the higher results of the Bulgarian and Croatian children is the good skills in Romani as their mother tongue. The Roma children from Slovakia and Czech Republic have low skills in Romani and they speak an ethnolect of the official language.

For Slovak and Czech children, the grammatical categories from the official language are more difficult because they do not learn them in any of the two languages - neither in Romani nor in the official language before to come to kindergarten

Coming back to the Roma tradition and how the Romani language is learned as a complex stricture and having in mind the principles of general linguistics of
Roma speak to their children using complex grammatical structures help them to acquire the complex grammatical structures of the L2 as well. This was our Hypothesis 1. Our Hypothesis 2 is that all Roma children will have the same difficulties learning the grammatical categories from their L2 is not conformed. The results showed that the difficulties in L2 depend from their knowledge in L1.

\section{Russian children}

The Russian children show very good knowledge in both tests. In Russian the use of the wh questions with two or three wh words at the beginning of the sentence is not normal. In Bulgarian and Croatian it is normal to say Koj kakvo pravi? (Bulgarian) and Tko što radi? (Croatian) literally who what is doing [Who is doing what]. In Romani is also normal to have two or three wh words at the beginning of the sentence. In Russian is normal to ask Kto delaet chto? It seems the Russian children learn the both types wh 
questions and wh complements by the age of 6 years. Some of Russian children did not answer exhaustively the two wh question in the first type of test. Their results are shown in the next Figure 4. knowledge of their mother tongue. They learn a language which is a mixture of Slovak/Czech and Romani languages. However, these does not mean that the children have language impairment or mental retardation.

\section{RUSSIAN CHILDREN}

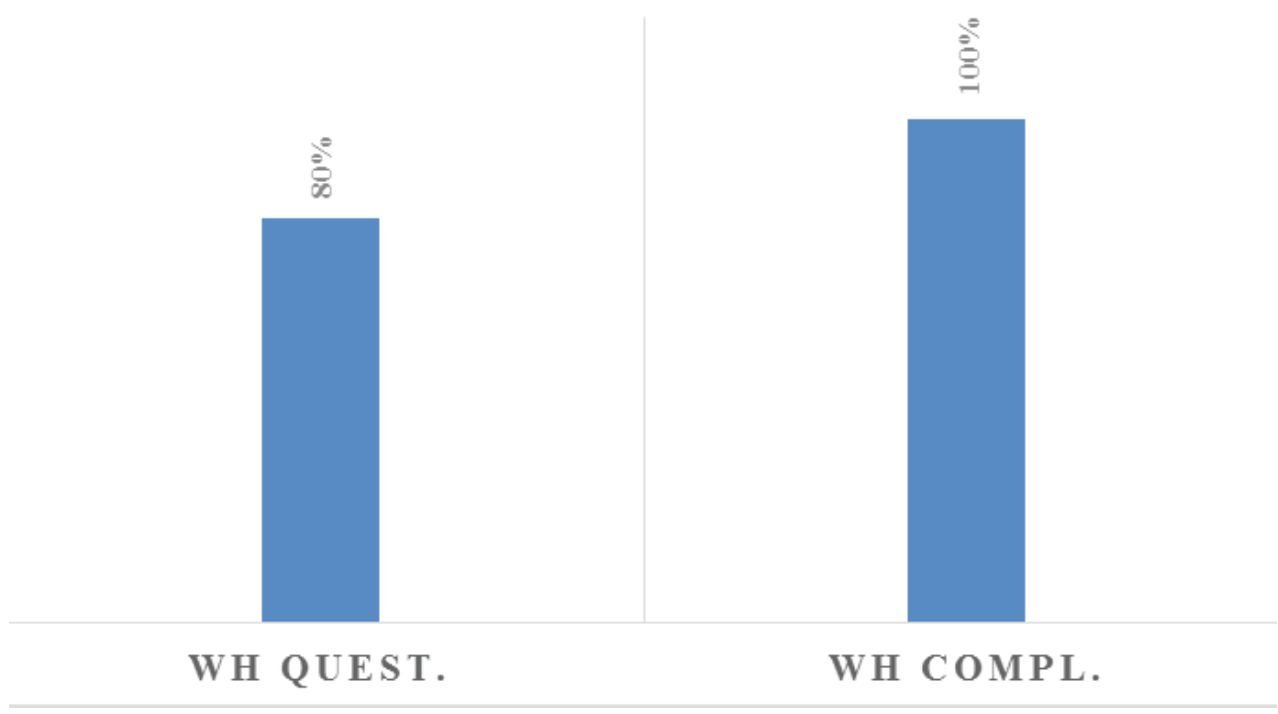

\section{Conclusions}

The present study, although limited in design (just two types of tests and limited number of children form each country, show important trends:

- The Roma children are normally developing children and they grow up bilingually and, in some cases, even multi-lingually (some of Croatian Roma children also speak Albanian, and some of the Slovak Roma children speak also Hungarian language). By the age of 5 years they acquire most of the grammatical categories of their mother tongue. This is the case with Bulgarian and Croatian children.

- The results of Roma children from Slovakia and Czech Republic are low, because the children do not have good
- The Russian children by the age of 6 already know perfectly well the syntax of the wh questions and wh complements in Russian their mother tongue. One part of bilingual Roma children also know well the wh-questions.

Based on this study, although limited in its design, we can conclude that monolingual and bilingual children, speakers of Slavic languages as L1 or L2, by the age of 6 years, get the same knowledge on the syntax structures. Those bilingual children who do not show good knowledge in L2 syntax do not have mental retardation, but rather their knowledge in the syntax of their mother tongue (L1) is limited. 


\section{References}

1. CENOZ J, GENESEE F (2001) Trends in Bilingual Acquisition. Amsterdam: John Benjamins Publ. Cummins J., Sayers D. (1995) Brave new schools. NY: St. Martin's Press.

2. DE HOWER A (2009) Bilingual first language acquisition. Bristol: Multilingual Matters.

3. GROSJEAN F (1982) Life with two languages: Cambridge: Harvard University Press.

4. GROSJEAN F (1994) Individual bilingualism. In: Encyclopedia of Language and Linguistics.Vol. 3, Oxford: Pergamon Press, pp. 1656-1660.

5. KYUCHUKOV H (2016) Bilingualism and Cross-cultural study of language and cognitive development. Psycholinguistics, 20, pp. 154-162.

6. ГУМБОЛЬДТ В (1984) Selected works on general linguistics. Москва.

7. СОХИН Ф А (2002) Psycho-pedagogical bases of language development of preschoolers. Москва.

8. УШАКОВА О С (2014) Patterns of acquisition of native language: development of linguistic and communicative abilities of children in preschool age. Москва: Сфера.

9. ЯШИНА В И, АЛЕКСЕЕВА М М (2017) Theory and methodology of language development of children. Москва: Академия 